\title{
Mathematical Expression of a Global Environmental Catastrophe
}

\author{
Daniel H. Rothman
}

Editor's Note: Daniel H. Rothman has kindly provided this explanation of the mathematics and science behind the preceding Mathematical Moment.

Two hundred and fifty-two million years ago, life on Earth nearly vanished [1]. So many marine animal species disappeared-more than 90 percent-that the event, known as the end-Permian extinction, qualifies as the most severe mass extinction in the geologic record. Unlike the later demise of the dinosaurs, the end-Permian extinction is not linked to a meteor impact. Yet it is unquestionably associated with major environmental change, including a strong perturbation of Earth's carbon cycle. Recently, an additional piece of the puzzle fell into place. Massive Siberian volcanism, long thought to coincide roughly with the extinction, is now known to have preceded it and continued beyond it [2].

A simple narrative emerges. Carbon dioxide degassed from millions of cubic kilometers of Siberian magma perturbed the carbon cycle, leading to an extreme form of our own contemporary concerns: global warming and ocean acidification. Life then nearly perished. It is an attractive story, but it fails. Geochemical studies reveal an influx of carbon dioxide that is much greater than Siberian volcanism would have provided on its own [3]. Something else must have happened.

Mathematics now enters the picture. The same advances that allow us to identify the chronological order of magma in Siberia and fossils elsewhere also make possible mathematical analyses of the temporal evolution of geochemical signals. These analyses then aid the development and testing of hypotheses, which in turn help to identify underlying mechanisms.

The best-understood geochemical signals are time series of the isotopic composition of carbon derived from

Daniel H. Rothman is professor of geophysics and codirector of the Lorenz Center at the Massachusetts Institute of Technology. His e-mail address is dhr@mit. edu.

For permission to reprint this article, please contact: reprint-permission@ams.org.

DOI: http://dx.doi.org/10.1090/noti1473

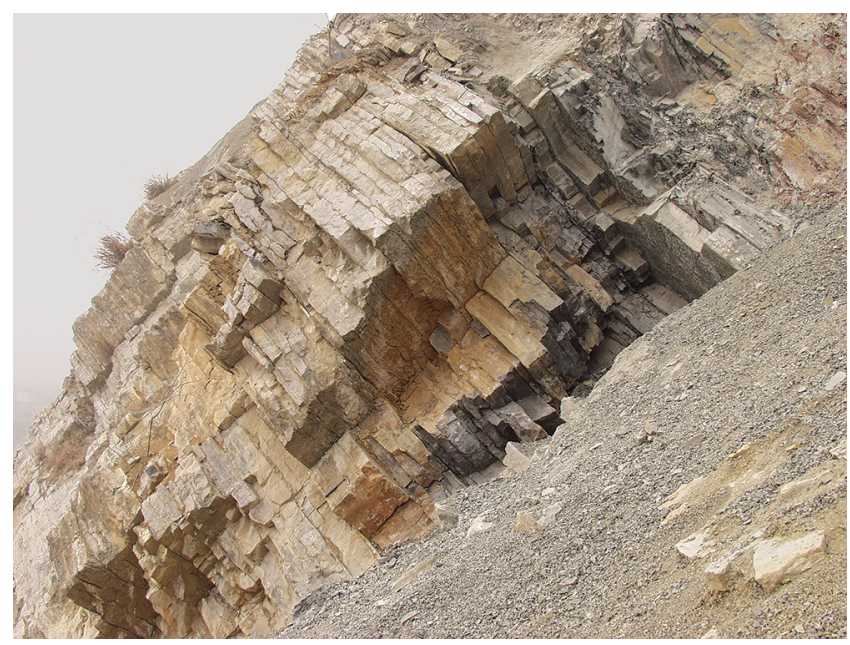

Figure 1: Sedimentary rocks located in Meishan, China. The layers represent a succession of marine sediments deposited before, during, and after the end-Permian extinction. The rocks contain chemical signatures of environmental conditions at the time of deposition. The arrow of time points upward, to the right.

sedimentary rocks (Figure 1). Carbon occurs as two stable isotopes, ${ }^{12} \mathrm{C}$ and ${ }^{13} \mathrm{C}$. The total mass of each isotope is conserved. But if we divide the world's carbon into two reactive global "reservoirs"-inorganic and organic carbon-the mass of ${ }^{12} \mathrm{C}$ and ${ }^{13} \mathrm{C}$ in each reservoir may vary. For example, the production of organic carbon from carbon dioxide by photosynthesis slightly favors the lighter isotope, so that organic carbon contains a smaller fraction of ${ }^{13} \mathrm{C}$ than the carbon dioxide from which it was produced. Geochemists measure the abundance ratio $R_{X}=\left({ }^{13} \mathrm{C} /{ }^{12} \mathrm{C}\right)_{X}$ in carbon of type $x$. Such isotopic data are reported in terms of the departure of this ratio from a standard ratio $R_{\text {std }}$ as the quantity

$$
\delta_{x}=\frac{R_{x}-R_{\text {std }}}{R_{\text {std }}} \times 1000,
$$



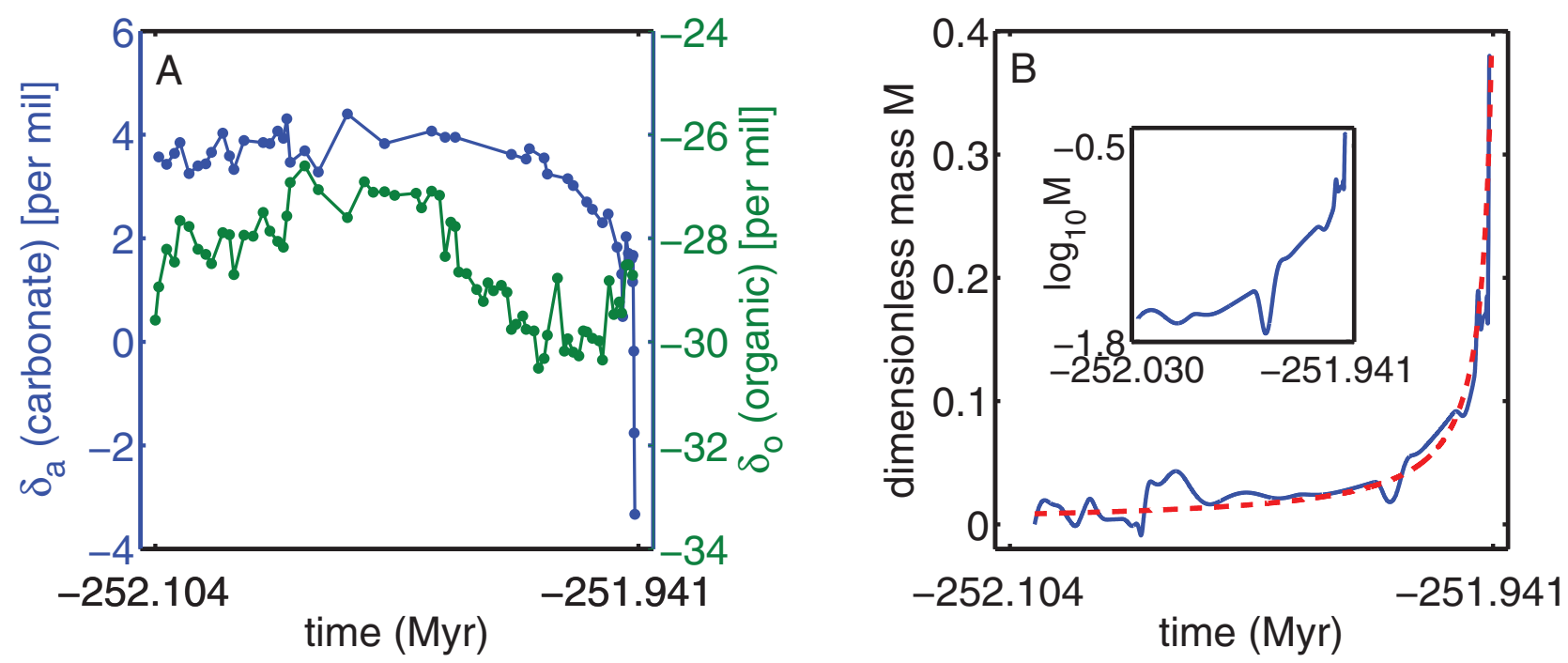

Figure 2: (A) The isotopic composition of inorganic (carbonate) and organic carbon in late-Permian sedimentary rocks, including those of Figure 1. The dates are accurate to within 0.02 percent [2]. The end-Permian extinction begins 251.941 million years ago and terminates $60 \pm 48$ thousand years later [2]. (B) Transformation of the geochemical signals in (A) to the accumulation of mass $M(t)$ of carbon added to the oceans (smooth blue curve), normalized with respect to the mass prior to perturbation. The red dashed line is the singular blowup of equation (2), with $t_{c}$ the onset time of the extinction. The curvature of the semilogarithmic plot in the inset shows that the growth of $M(t)$ is faster than exponential. Modified from [4].

where multiplication by 1000 means that the units are parts per thousand, or per mil. Time series for inorganic (carbonate) carbon $\left(\delta_{a}\right)$ and organic carbon $\left(\delta_{o}\right)$ are shown in Figure 2a. The evolution of $\delta_{a}(t)$ is consistent with a growing perturbation in which isotopically light carbon increasingly fills the inorganic pool. In the following, I describe a recent collaborative effort to characterize this evolution mathematically and to interpret the results [4].

First, equations for the conservation of ${ }^{12} \mathrm{C}$ and ${ }^{13} \mathrm{C}$ and their exchange via photosynthesis and respiration (i.e., the oxidation of organic carbon to carbon dioxide) are inverted to estimate the time-dependent flux of isotopically light organic carbon consistent with the signals in Figure 2a. Integrating that flux, we obtain the accumulated mass $M(t)$ of carbon added to the inorganic pool, normalized with respect to the initial mass of that pool. The result, in Figure $2 \mathrm{~b}$, suggests that $M(t)$ grows like an incipient singular blowup of the form

$$
M(t) \propto \frac{1}{t_{c}-t},
$$

where $t_{c}$ is the onset of the extinction. Noting that equation (2) solves $\mathrm{d} M / \mathrm{d} t \propto M^{2}$, we conclude that we have detected a nonlinear interaction within the carbon cycle. But what is that interaction? And how does it lead to equation (2)?

It has long been recognized that population dynamics can exhibit growth like equation (2) [5]. Exponential growth is more common, but if per capita growth rates increase with population size (due, e.g., to improved technology) and resources are effectively unlimited, superexponential growth ensues. We know from geochemical analyses that
late-Permian sediments contain unusually high concentrations of organic matter. Such organic matter is usually metabolized by microbes deep beneath the seafloor, but its decay was somehow hindered. Now suppose that a new metabolic pathway evolved to consume this stockpile. Microbes endowed with the new pathway would then proliferate.

To pursue this line of reasoning, we hypothesized that a previously identified genomic innovation was favored by the end-Permian environment. The new pathway allowed a particular genus of microbes, Methanosarcina, to convert acetate, a form of organic carbon, to methane more efficiently than before. The oxidation of the methane to carbon dioxide would then provide the required flux of isotopically light carbon. Using methods of computational genomics, we found that the new pathway evolved $240 \pm 41$ million years ago. The date is propitious, but its degree of uncertainty is undesirable. One would like more evidence.

Further support follows from two facts: Methanosarcina requires nickel to make methane. And the world's largest economic concentration of nickel is located in Siberia, having been deposited during the period of massive Siberian volcanism. If the nickel entered the oceans, then elevated nickel concentrations would have removed a significant barrier to the expansion of Methanosarcina. Our group measured the concentration of nickel in the same rocks that yielded the carbon isotopic data of Figure 2a. We found that nickel concentrations increase abruptly just before the blowup. Moreover, subsequent dating of Siberian nickel deposits confirms that nickel-rich lavas erupted prior to the extinction [2]. 


\section{COMMUNICATION}

A mathematical story is now straightforwardly written. Let the total production of methane by the new pathway be $A \propto M$. Note that methane producers live where there is no free oxygen and that the conversion of methane to carbon dioxide consumes oxygen. Consequently the carrying capacity $K$-i.e., the maximum population supported by the environment-for Methanosarcina grows as its population grows, because its anoxic niche becomes larger while its resources (acetate and nickel) remain abundant. In other words, $K$ grows with $A$, like

$$
K(t)=k_{0}+k_{1} A(t),
$$

where $k_{0}$ is the initial carrying capacity and $k_{1}>0$ is a constant. The rate at which methane is produced scales like the carrying capacity:

$$
\mathrm{d} A / \mathrm{d} t=\beta K,
$$

where $\beta>0$ is related to the metabolic rate of an individual organism. If $\beta$ is constant, $A(t)$ grows exponentially. However, it may not be constant. For example, new species of Methanosarcina may evolve to take advantage of specialized niches, or the expansion of Methanosarcina may bring it closer to nutrients that limit its growth. Thus it is reasonable to imagine $\beta$ growing with $A$. The simplest relation would be linear:

$$
\beta(t)=\beta_{0}+\beta_{1} A(t),
$$

where $\beta_{0}$ and $\beta_{1}$ are positive constants. Inserting (5) and (3) into (4), we find that $\mathrm{d} A / \mathrm{d} t$ grows quadratically with $A$ for large $A$; thus, to leading order, $A \propto\left(t_{c}-t\right)^{-1}$ as $t \rightarrow t_{c}$.

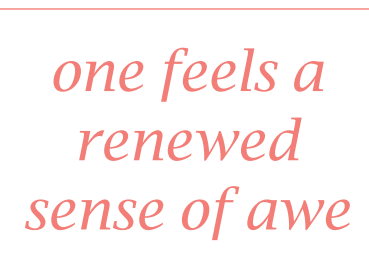

Our story has the virtue of fitting the observations, but it is presumably not unique. It nevertheless contains two valuable lessons. First, it provides new insight into the ways in which microbial evolution impacts not only the global environment but also the evolution of macroscopic life. Second, it shows how mathematics can play a foundational role in developing such insight. Manifestations of mathematics in nature are not new. But when one can look back a quarter of a billion years and see a mathematical expression of Earth's greatest natural catastrophe, one feels a renewed sense of awe. Can it all really be so simple? Indeed it can.

ACKNOWLEDGMENTS. I thank the coauthors of [4] for their valuable collaboration. This work was supported by NASA Astrobiology grant NNA13AA90A.

\section{References}

[1] D. H. ERwin, Extinction: How Life on Earth Nearly Ended 250 Million Years Ago, Princeton University Press, Princeton, NJ, 2006.

[2] S. D. Burgess and S. A. BowRING, High-precision geochronology confirms voluminous magmatism before, during, and after Earth's most severe extinction, Science Advances, 1(7) (2015), e1500470.
[3] R. A. BERner, Examination of hypotheses for the PermoTriassic boundary extinction by carbon cycle modeling, Proc. Natl. Acad. Sci. USA 99(7) (2002), 4172-4177.

[4] D. H. Rothman, G. P. Fournier, K. L. French, E. J. Alm, E. A. Boyle, C. CAO, and R. E. Summons, Methanogenic burst in the end-Permian carbon cycle, Proc. Natl. Acad. Sci. USA 111(5) (2014), 5462-5467.

[5] H. Von Foerster, P. M. MORA, and L. W. AMIOT, Doomsday: Friday, 13 November, AD 2026, Science 132(3436) (1960), 1291-1295.

\section{Photo Credits}

Photo of sedimentary rocks is courtesy of Shuzhong Shen.

Photo of Daniel H. Rothman is courtesy of Francis Ö. Lustwerk-Dudás.

\section{ABOUT THE AUTHOR}

The author in South China. His right hand lies on the geologic boundary between the Permian and Triassic periods. Back home at MIT, he is cofounder and codirector of the Lorenz Center, which is devoted to developing the foundations of climate science.

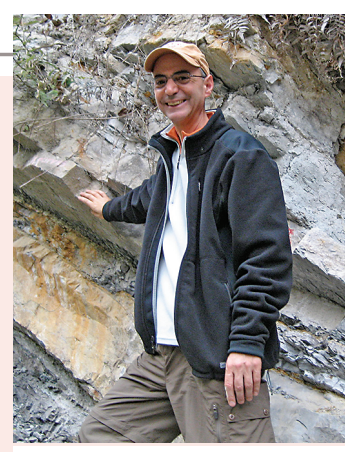

Daniel H. Rothman 